\title{
An empirical investigation on psychological characteristics of entrepreneurs
}

\author{
Masoumeh sadat Abtahi ${ }^{a^{*}}$, Farhad Edrisi $^{\mathrm{a}}$ and Kobra Abbasi ${ }^{\mathrm{b}}$
}

${ }^{a}$ Department of Humanities, Zanjan branch, Islamic Azad University, Zanjan, Iran

${ }^{b}$ Department of Humanities, Research and science Zanjan branch, Islamic Azad University, Zanjan, Iran

\section{CHRON I C L E}

Article history:

Received August 16, 2013

Received in revised format

12 September 2013

Accepted 1 November 2013

Available online

November 22013

Keywords:

Psychological characteristics of

entrepreneurs

Locus of control

Risk taking

Tolerance of ambiguity

\section{A B S T R A C T}

This paper presents an empirical investigation on psychological characteristics of entrepreneurs in one of Iranian universities located in city of Zanjan, Iran. The proposed study of this paper uses a standard questionnaire in Likert scale and concentrates on three components of locus of control, risk taking and tolerance of ambiguity. The study chooses a sample of 350 out of 11,000 students who were enrolled in various areas and detected that students maintained higher level of risk taking $(\mathrm{t}$-student $=10.999, \mathrm{P}$-value $=0.000)$, higher level of locus of control ( $\mathrm{t}$-student $=29.708, \mathrm{P}$-value $=0.000)$ and lower level of tolerance of ambiguity ( $\mathrm{t}$ student $=-13.584$, P-value $=0.000$ ).

(C) 2013 Growing Science Ltd. All rights reserved.

\section{Introduction}

Personal characteristics of entrepreneurs are considered as the most important parameters on creating jobs and opportunities in organizations. Many entrepreneurs are the people who first attend at university and college, create some ideas and then try to develop their ideas. One of the most important things is to see how personal characteristics shape their lives. There are literally various studies on psychological characteristics of entrepreneurs. Ahmadkhani et al. (2013) presented an empirical study on personal characteristics of some students who were supposed to act as entrepreneur to create jobs in two major fields of engineering and social sciences. There are eight aspects of accepting reasonable risk, locus of control, the need for success, mental health conditions, being pragmatic, tolerating ambiguity, dreaming and the sense of challenging in this study to measure the level of entrepreneurship. The results of their survey confirmed that the students who were enrolled in social sciences accepted a reasonable amount of risk, maintained sufficient locus of 
control, wished to reach prosperity and success in their carrier and lives and enjoyed a good level of dreaming.

Palifka (2009) examined the effects of 11 personality traits on compensation among college graduates in Mexico. With matched employee-supervisor surveys, the study indicated that self-assessments and supervisor assessments of the same traits differed, and estimated the marginal effects of each on compensation. Gupta and Fernandez (2009) investigated characteristics attributed to entrepreneurs in three countries and identified similarities and differences in entrepreneurial characteristics across countries. They reported that though some characteristics had been attributed to entrepreneurs across national cultures. There were also important differences in characteristics attributed to entrepreneurs in the three cultures.

Harris and Gibson (2008) investigated the entrepreneurial behaviors of undergraduate students enrolled in the Small Business Institute ${ }^{\circledR}$ (SBI) program at multiple universities in the USA. They reported that the majority of students possessed entrepreneurial attitudes. In addition, both student characteristics and entrepreneurial experience were detected to be associated with certain entrepreneurial attitudes, male students scored higher on both personal control and innovation, and students with family business experience maintained more developed entrepreneurial attitudes.

Khorshidifar and Abedi (2010) did an empirical investigation on the impact of stress on the relationship between locus of control and job satisfaction and job performance. They chose a sample size of 65 senior and regular accountants who worked for thirteen different regional municipalities of city of Mashad located in east part of Iran and applied various well-known questionnaire techniques such as stress diagnostic survey, locus of control, job satisfaction and employees' performance to perform the study. They reported that the stress had been on average level for the dominant locos of control factors and job satisfaction and employee performance had been in relatively high level.

Zampetakis (2008) studied the role of creativity and proactivity on perceived entrepreneurial desirability. Zhou (2007) applied an investigation on the effects of entrepreneurial proclivity and foreign market knowledge on early internationalization. Ucbasaran et al. (2010) studied on the nature of entrepreneurial experience, business failure and comparative optimism. Lin (2006) studied on the trends of entrepreneurial behaviors of enterprises in various strategies.

Nicholson (1998) tried to find an appropriate answer to the question of whether there was an entrepreneurial leadership personality profile using an empirical investigation of the heads of the UK's top independent firms and compared them with sample norms and a management control group. Wijbenga and van Witteloostuijn (2007) studied the impact of environmental dynamism on entrepreneurial locus of control-competitive strategy relationship and stated that internal entrepreneurs executed product innovation strategies in stable environments, whereas external entrepreneurs opt for low-cost strategies in dynamic environments.

Brush et al. (2009) proposed some pathways to entrepreneurial growth by looking into the effect of management, marketing and money. They explained that fast-growing firms could exhibit different rates and patterns of growth including some represent fast growth trajectories. They also reported that three key factors - management, marketing, and money-influenced company growth across these patterns. Obschonka et al. (2010) stated that entrepreneurial intention might be the key success for new ideas. Schmitt-Rodermund (2004) introduced four basic characteristics of parenting, personality, early entrepreneurial competence, and interests for the success of entrepreneurship. The author stated that an early start-up and an entrepreneurial personality of the founder could be considered as important factors. 


\section{Problem statement}

In this paper, we select a sample size from all students who were enrolled in various fields of sciences at Islamic Azad University located in city of Zanjan, Iran. The sample size is calculated as follows,

$n=\frac{N \times z_{\alpha / 2}^{2} \times p \times q}{\varepsilon^{2} \times(N-1)+z_{\alpha / 2}^{2} \times p \times q}$,

where $N$ is the population size, $p=1-q$ represents the yes/no categories, $z_{\alpha / 2}$ is CDF of normal distribution and finally $\varepsilon$ is the error term. Since we have $p=0.5, z_{\alpha / 2}=1.96, \varepsilon=0.05$ and $N=11000$, the number of sample size is calculated as $n=350$. The questionnaire was designed based on Likert scale (Likert, 1932).

The proposed study of this paper considers the following eight hypotheses,

1. Students accept of risk taking (RT).

2. Students have desirable level of locus of control (LOC).

3. Students maintain tolerance of ambiguity (TA).

The proposed study attempts to use Pearson correlation test but we first have to make sure about the normality of data using Kolmogorov-Smirnov, which is summarized in Table 1 as follows,

\section{Table 1}

The summary of normality test using Kolmogorov-Smirnov

\begin{tabular}{lcc}
\hline Variable & Sig. & Result \\
\hline Risk taking (RT) & 0.129 & Confirmed \\
Locus of control (LOC) & 0.53 & Confirmed \\
Tolerance of ambiguity (TA) & 0.105 & Confirmed \\
\hline
\end{tabular}

As we can observe from the results of Table 1, all three components of the survey are normally distributed and the level of significance is five or even one percent. Next, we present details of our findings on testing three hypotheses of the survey.

\section{Results}

In this section, we present details of our finding on eight hypotheses.

\subsection{Accepting desirable level of risk}

The first hypothesis is associated with the level of risk they could accept.

$\int H_{0}$ : Students do not accept sufficient level of risk

$H_{1}$ : Students accept sufficient level of risk

Table 2 shows details of our finding,

Table 2

The results of some basic statistics associated with the first hypothesis

\begin{tabular}{lcccc}
\hline Group & Number & Mean & Standard deviation & Standard error \\
\hline Risk taking & 350 & 50.52 & 9.38 & 0.50 \\
\hline
\end{tabular}


In this paper, we use the following hypothesis to test the first hypothesis,

$\mathrm{H}_{0}: \mu \leq 45$

$\mathrm{H}_{1}: \mu>45$

As we can observe from the results of Table 2, mean of numbers is equal to $50.52>45$ and we can reject the null hypothesis. In addition, Table 3 shows details of t-student test.

\section{Table 3}

The summary of t-student test

\begin{tabular}{lccccc}
\hline Statistics & t-student & df & Sig. & Lower & Upper \\
\hline Risk taking & 10.999 & 349 & 0.000 & 4.53 & 5.51 \\
\hline
\end{tabular}

As we can observe from the results of Table 3, we have a meaningful level of t-student, which means we can reject the null hypothesis and conclude that the students accept a reasonable amount of risk.

\subsection{Locus of control}

The second hypothesis is associated with the locus of control.

$\begin{cases}H_{0}: & \text { Students do not have desirable locus of control } \\ H_{1}: & \text { Students have desirable locus of control }\end{cases}$

Table 4 demonstrates details of our test,

Table 4

The results of some basic statistics associated with the second hypothesis

\begin{tabular}{lcccc}
\hline Group & Number & Mean & Standard deviation & Standard error \\
\hline Locus of control & 350 & 54.95 & 7.84 & 0.42 \\
\hline
\end{tabular}

In this paper, we use the following hypothesis to test the second hypothesis,

$\mathrm{H}_{0}: \mu \leq 42.5$

$\mathrm{H}_{1}: \mu>42.5$

Table 5

The summary of t-student test

\begin{tabular}{lccccc}
\hline Statistics & t-student & df & Sig. & Lower & Upper \\
\hline Locus of control & 29.708 & 349 & 0.000 & 11.62 & 12.44 \\
\hline
\end{tabular}

Once more, based on the results of Table 5, we can reject the null hypothesis and conclude that the students maintain sufficient locus of control.

\subsection{Tolerance of ambiguity}

The third hypothesis is associated with their sense of tolerating ambiguity (TA)

$\left\{H_{0}: \quad\right.$ Students are not able to handle ambiguity

$H_{1}$ : $\quad$ Students are able to handle a sufficient level of ambiguity

Table 6 demonstrates details of some basic statistics, 
Table 6

The results of some basic statistics associated with the third hypothesis

\begin{tabular}{lcccc}
\hline Group & Number & Mean & Standard deviation & Standard error \\
\hline Tolerance of ambiguity & 350 & 23.04 & 6.14 & 0.33 \\
\hline
\end{tabular}

In this paper, we use the following hypothesis to test the second hypothesis,

$\mathrm{H}_{0}: \mu \leq 27.5$

$\mathrm{H}_{1}: \mu>27.5$

In addition, Table 7 shows details of our survey on testing the third hypothesis using t-student.

Table 7

The summary of t-student test

\begin{tabular}{lccccc}
\hline Statistics & t-student & df & Sig. & Lower & Upper \\
\hline Tolerance of ambiguity & -13.584 & 349 & 0.000 & -5.10 & -4.45 \\
\hline
\end{tabular}

Once more, based on the results of Table 7, we cannot reject the null hypothesis and conclude that the students could not tolerate ambiguity and the third hypothesis of the survey was not confirmed.

\section{Conclusion}

In this paper, we have presented an empirical investigation to study the effects of three personal characteristics of the students who were enrolled in a private school in Iran. The results of the survey on the first two hypotheses, risk taking and Locus of control are consistent with the results found by Ahmadkhani et al. $(2012,2013)$. The primary focus of this survey was only three components of physiological characteristics of entrepreneurs. The survey can be extended for other personal characteristics such as the need for success, mental health conditions, being pragmatic, etc. and we leave it for future research.

\section{Acknowledgement}

The authors would like to thank the anonymous referees for constructive comments on earlier version of this paper.

\section{References}

Ahmadkhani, A., Paknezhad, M., \& Nazari, A. (2012). An empirical study on entrepreneurs' personal characteristics. Management Science Letters, 2(3), 751-756.

Ahmadkhani, A., Heydari, L., Heydari, M \& Panahandeh, G. (2013). Investigating personal characteristics of entrepreneurs. Management Science Letters, 3(11), 2717-2724.

Brush, C.G., Ceru, D.J., \& Blackburn, R. (2009). Pathways to entrepreneurial growth: The influence of management, marketing, and money. Business Horizons, 52(5), 481-491.

Cronbach, L. J. (1951). Coefficient alpha and the internal structure of tests. Psychometrika, 16(3), 297-334.

Friedman, M. (1940). A comparison of alternative tests of significance for the problem of $\mathrm{m}$ rankings. The Annals of Mathematical Statistics, 11 (1), 86-92.

Gupta, V., \& Fernandez, C. (2009). Cross-Cultural Similarities and Differences in Characteristics Attributed to Entrepreneurs A Three-Nation Study. Journal of Leadership \& Organizational Studies, 15(3), 304-318.

Harris, M. L., \& Gibson, S. G. (2008). Examining the entrepreneurial attitudes of US business students. Education + Training, 50(7), 568-581. 
Khorshidifar, M., \& Abedi, A. (2010). An empirical study on the impact of stress on the relationship between locus of control and job satisfaction and job performance. Management Science Letters, 4(1), 511-516.

Likert, R. (1932). A Technique for the Measurement of Attitudes. Archives of Psychology, 140, 1-55.

Lin, W.B. (2006). A comparative study on the trends of entrepreneurial behaviors of enterprises in different strategies: Application of the social cognition theory. Expert Systems with Applications, 31(2), 207-220.

Nicholson, N. (1998). Personality and entrepreneurial leadership: A study of the heads of the UK's most successful independent companies. European Management Journal, 16(5), 529-539.

Obschonka, M., Silbereisen, R. K., Schmitt-Rodermund, E. (2010). Entrepreneurial intention as developmental outcome. Journal of Vocational Behavior, 77(1), 63-72.

Palifka, B. J. (2009). Personality and income in Mexico: Supervisor assessments vs. selfassessments. Journal of Economic Psychology, 30(1), 92-106.

Schmitt-Rodermund, E. (2004). Pathways to successful entrepreneurship: Parenting, personality, early entrepreneurial competence, and interests. Journal of Vocational Behavior, 65(3), 498-518.

Ucbasaran, D., Westhead, P., Wright, M., \& Flores, M. (2010). The nature of entrepreneurial experience, business failure and comparative optimism. Journal of Business Venturing, 25(6), 541555.

Wijbenga, F.H., \& van Witteloostuijn, A. (2007). Entrepreneurial locus of control and competitive strategies - The moderating effect of environmental dynamism. Journal of Economic Psychology, 28(5), 566-589.

Zampetakis, L.A. (2008). The role of creativity and proactivity on perceived entrepreneurial desirability. Thinking Skills and Creativity, 3(2), 154-162.

Zhou, L. (2007). The effects of entrepreneurial proclivity and foreign market knowledge on early internationalization. Journal of World Business, 42(3), 281-293. 